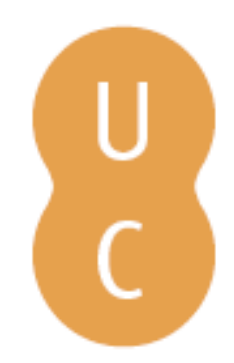

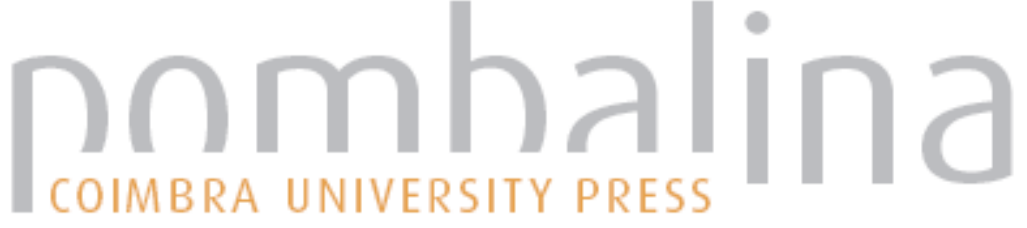

\section{Large airtanker use in the United States: what do we know?}

Autor(es): $\quad$ Thompson, Matthew P; Stonesifer, Crystal; Calkin, David E

Publicado por: Imprensa da Universidade de Coimbra

URL

persistente: URI:http://hdl.handle.net/10316.2/34337

DOI: $\quad$ DOI:http://dx.doi.org/10.14195/978-989-26-0884-6_93

Accessed : $\quad$ 26-Apr-2023 14:34:04

A navegação consulta e descarregamento dos títulos inseridos nas Bibliotecas Digitais UC Digitalis, UC Pombalina e UC Impactum, pressupõem a aceitação plena e sem reservas dos Termos e Condições de Uso destas Bibliotecas Digitais, disponíveis em https://digitalis.uc.pt/pt-pt/termos.

Conforme exposto nos referidos Termos e Condições de Uso, o descarregamento de títulos de acesso restrito requer uma licença válida de autorização devendo o utilizador aceder ao(s) documento(s) a partir de um endereço de IP da instituição detentora da supramencionada licença.

Ao utilizador é apenas permitido o descarregamento para uso pessoal, pelo que o emprego do(s) título(s) descarregado(s) para outro fim, designadamente comercial, carece de autorização do respetivo autor ou editor da obra.

Na medida em que todas as obras da UC Digitalis se encontram protegidas pelo Código do Direito de Autor e Direitos Conexos e demais legislação aplicável, toda a cópia, parcial ou total, deste documento, nos casos em que é legalmente admitida, deverá conter ou fazer-se acompanhar por este aviso. 


\section{ADVANCES IN}

Forest Fire

\section{RESEARCH}

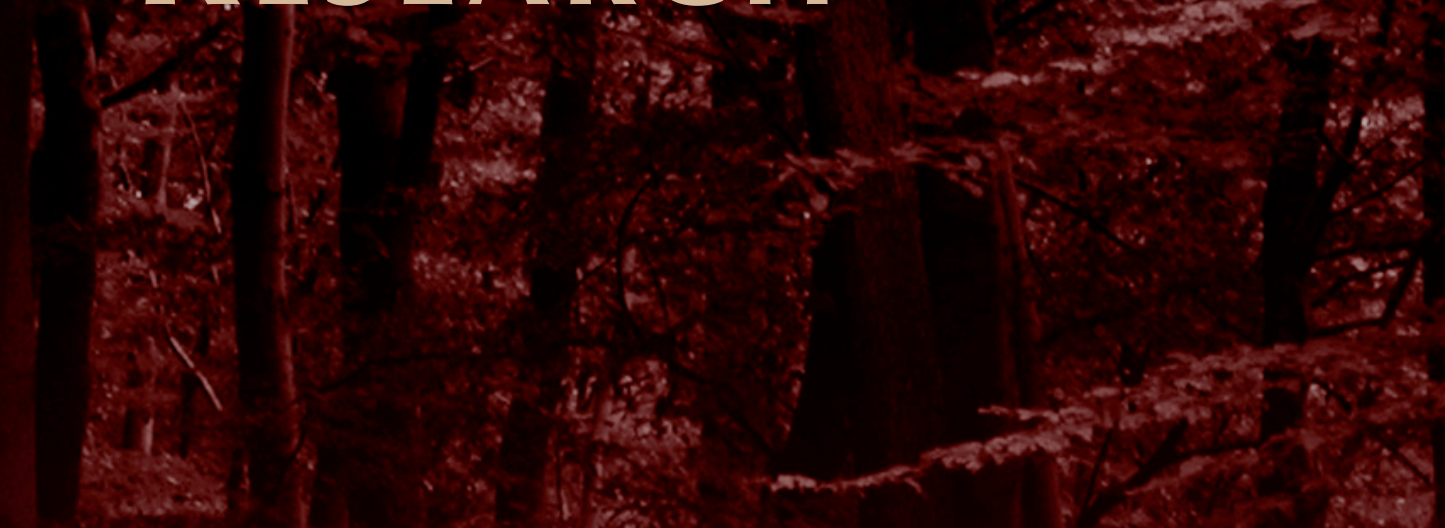

\section{DOMINGOS XAVIER VIEGAS}

\section{EDITOR}




\title{
Large airtanker use in the United States: what do we know?
}

\author{
Matthew P Thompson, Crystal Stonesifer, and David E Calkin
}

Rocky Mountain Research Station, US Forest Service, Missoula, MT, USA, mpthompson02@fs.fed.us, csstonesifer@fs.fed.us, decalkin@fs.fed.us

\begin{abstract}
In this paper we will review recently uncovered trends in large airtanker (LAT) use in the U.S., explore implications, and discuss opportunities for improving efficiencies. First, we will review results of two studies attempting to characterize LAT use between initial attack (IA) and extended attack and/or large fire support (EA) missions. Collectively these studies identified significant LAT use for EA despite a history of prioritizing LATs for IA, and further identified potentially counterintuitive results where fires receiving LAT support during IA were more likely than not to escape IA efforts. These results suggest potential operational efficiencies in LAT use, and that improving success in IA efforts may be in part premised on reducing the time between ignition and LAT arrival on the fire. Here we examine trade-offs between LAT usage for IA and LAT unavailability for IA operations due to EA use. To do so we use a mathematical optimization model to identify efficient LAT air base location and deployment strategies. The model is designed to minimize the total deployment time of meeting LAT IA demand, with demand quantified as a function of a fire weather index. Results indicate, as expected, that model performance degrades as LATs are increasingly unavailable. Results further indicate substantial sensitivity of LAT air base location strategy to LAT availability, with potentially significant implications for air base staffing and capacity decisions, as well as fleet composition decisions. To conclude we will describe ongoing and future work analysing opportunities for efficiency gains in LAT management, focusing on the role of forecasting and optimization frameworks, as well as ongoing data collection and analysis regarding retardant drop conditions and outcomes.
\end{abstract}

Keywords: initial attack, resource use, large fire management, efficiency

The views expressed here are the authors', and do not necessarily represent the views of the USDA

\section{Introduction}

Large airtankers (LATs) are part of a broader suite of aviation assets including scoopers, helicopters, and single-engine airtankers, each with different operational capacities and limitations that can perform a wide variety of mission critical activities. LATs are prized for their large storage capacity and their ability to quickly travel to fire starts to facilitate containment during initial attack operations. Nominally, initial attack has been the primary role for LATs in federal fire suppression in the United States. Subsequently, optimization models supporting LAT fleet composition and location-allocation decisions are premised on the primary use of LATs being for initial attack (Fire Program Solutions 2005; Keating et al. 2012). These analyses have great policy relevance, as the U.S. Forest Service is facing decisions about how best to address an aging fleet of contracted aircraft. Questions to consider include whether to contract or purchase aircraft, how many aircraft to contract/purchase, of which type, in what mix, with what equipment, and for what role.

But is initial attack really the primary role for federally contracted LATs in the United States? And do the data exist to support comprehensive analysis of the costs and benefits of alternative fleet composition strategies? In 2013 the U.S. Government Accountability Office (GAO) released the findings of an investigation into federal agency actions regarding their fleet modernization and analysis efforts, which identified a need for improved data collection systems (GAO 2013). Similarly, our past and ongoing research has identified inadequacies and deficiencies in data collection, ranging from a limited ability to track and characterize LAT use at the national level, to an even more limited ability 
to characterize the objectives and outcomes of individual drops at the incident level. Fine-scale evaluation of LAT drop effectiveness is the fundamental piece of information for supporting decisions related to choosing efficient combinations of aviation and ground-based firefighting resources and establishing appropriate flight mission objectives at the incident-level, for prepositioning and dispatch decisions across multiple incidents, and ultimately for arriving at efficient aviation resource mixes across fire seasons at the national level. Fortunately, recent work in the U.S. and elsewhere around the globe is providing new data and tools to better characterize the costs and benefits of aerial suppression efforts.

Three recent studies are particularly relevant to analyses of aerial firefighting effectiveness and efficiency. First, Plucinski and Pastor (2013) outlined a set of criteria and methodologies for evaluating the effectiveness of aerial suppression drops, and applied their methods during field fire experiments performed in eastern South Australia. The authors identified information needs for environmental and delivery conditions to support evaluation of drop effectiveness, including characteristics related to the type of aircraft, the drop location, fire behaviour, and ground suppression activities. Questions related to evaluation of drop success include whether a drop objective was clearly defined, whether drop placement and coverage were sufficient, and whether spatiotemporal effects on fire behaviour met drop objectives. In the U.S. the ongoing Aerial Firefighting Use and Effectiveness study will ideally be able to provide much of this information, but in the interim critical knowledge gaps remain.

Second, Thompson et al. (2013) examined the availability and sufficiency of U.S. federal agency aviation data to support cost-effectiveness analysis, finding that significant data quality issues and limited interoperability across data management systems precluded an in-depth analysis of the sort recommended by Plucinski and Pastor (2013). Instead, the authors as a first step summarized LAT flights according to mission type (initial attack (IA) versus extended attack and/or large fire support (EA)) across the years 2007-2010, using information on both the flight's job code description, and fire size class at the time of the drop. Depending upon assumptions for how to group job codes, results indicated that somewhere between $6.6 \%$ and $48.1 \%$ of flights were used for IA operations. Fire size results similarly showed limited usage for IA $(10.8 \%)$, and further indicated extensive use on very large fires. Nearly $35 \%$ of drops occurred on fires larger than 4,047 ha (10,000 ac), and nearly $23 \%$ of flights occurred on fires larger than 8,094 ha (20,000 ac).

Third, in a more in-depth study, Calkin et al. (2014) linked spatially-explicit drop location data with fire occurrence and firefighting resource ordering records to better identify the period in the fire history when drops occurred as well as the resulting outcomes of fires that received drops during IA. The authors analysed LAT drops across 2010-2011, and results confirmed earlier work indicating extensive use of LATs on EA. In 2010, a relatively quiet fire season, $34.4 \%$ of all drops were used in EA; this increased to $50.9 \%$ in 2011 . The number of drops per incident exhibited high variability, largely a reflection of heavy usage for significant events during EA operations, including multiple incidents with more than 75 drops. Results further indicated that drops during IA tended to be associated with incidents that escaped IA and transitioned into EA. In 2010, $67.5 \%$ of IA LAT use incidents eventually escaped, and this increased to $84.8 \%$ in 2011.

Results of these two latter studies highlight possible inadequacies in contemporary LAT usage, as well as significant complexities in quantifying cost-effectiveness given limited understanding of the marginal contribution of LAT usage to reduced damage across of the spectrum of LAT drop objectives during EA operations. That the majority of overall drops occurred during EA operations suggests that LATs are "sticky" and that fire managers tend to retain LATs for use outside of what has historically been considered their most suitable role. EA LAT use could still be cost-effective under a range of circumstance, of course, but potentially comes at the cost of diverting resources from IA demands. Additionally, that a large majority of drops occurring during IA are associated with escaped wildfires suggests that fire managers are appropriately calling for LAT support on incidents with high escape potential, but also suggests inefficiencies in the positioning, dispatch, availability, and delivery of 
LATs for IA operations. The degree to which LAT use on EA can directly degrade IA operational efficiencies has yet to be rigorously quantified, however.

In this paper, we rely on a formalized optimization framework to better understand trade-offs in LAT usage patterns, with the aim to generate information useful for future cost-effectiveness analyses. Specifically we build upon a resource allocation model tested on a select set of units managed by the California Department of Forestry and Fire Protection (Chow and Regan 2011). We develop a static allocation model where LATs are assigned to the same air base for the entire season, and focus on isolating the influence of systemic LAT unavailability for IA due to use for EA operations. In the following sections we introduce the reformulated optimization model along with a sensitivity analysis, present results, discuss implications, and offer recommendations for future research.

\section{Model Formulation}

Our model expands upon a previously developed model by Chow and Regan (2011), and has similarities to facility location problems. The problem is defined as the allocation of LATs to air bases over the course of a fire season to minimize the cost (using travel time as a proxy) of deploying LATs to wildfires. The problem formulation is designed to recognize important features of LAT location and deployment, such as the potential demand for multiple LATs to respond to a wildfire, and the ability to co-locate multiple LATs at a given air base. Demand for LATs is dependent upon location-specific seasonal averages for the National Fire Danger Rating System's Burning Index. Structurally, the problem considers a network of nodes (air bases) and arcs with fixed travel times between air bases. Model outputs include assignments of LAT air base locations as well as LAT deployment rules to cover LAT demand from other air bases. We expand upon this formulation by accounting for the possibility of LATs being unavailable for IA due to EA use, and explore how total deployment time changes with various LAT availability rates.

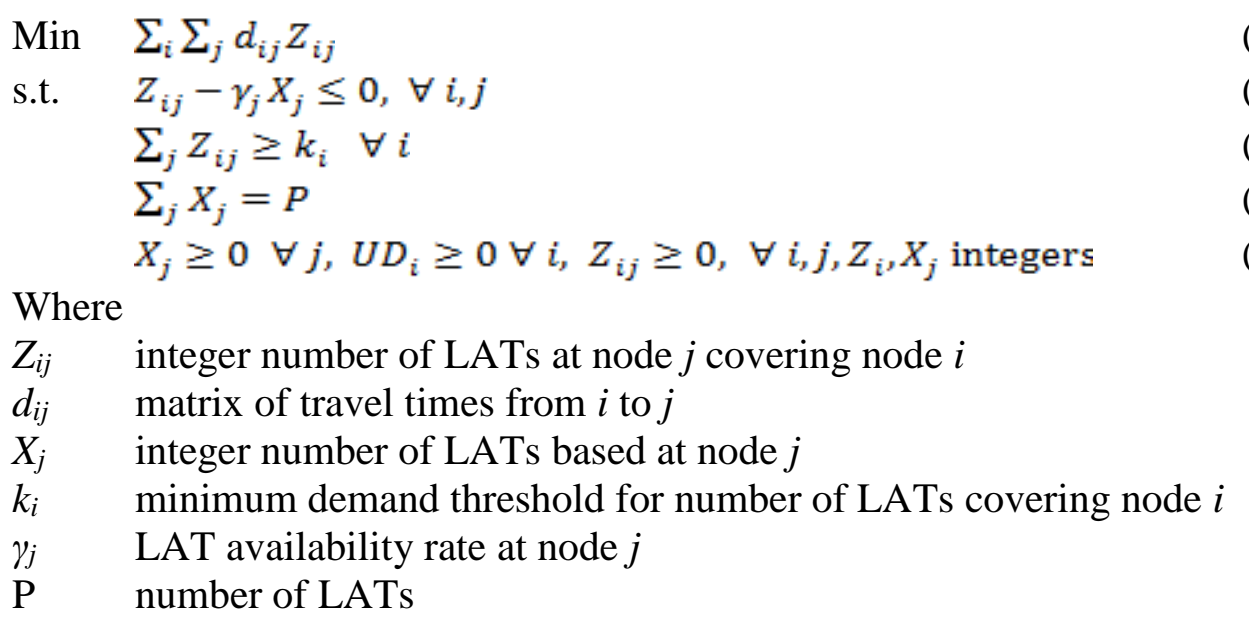

Equation 1 minimizes the travel times of the closest tanker bases delivering LATs to demand nodes. Equation 2 limits the number of LATs that can be assigned to node $i$ by the availability-weighted number of LATs at node $j$. Equation 3 forces assignment of the $k$ closest available LATs to node $i$. Lastly, Equation 4 limits assignment of LATs to the total number of LATs in the fleet, and Equation 5 ensures non-negativity.

To examine the sensitivity of model performance to LAT availability, we first uniformly vary LAT unavailability rates in 0.05 increments from 0.05 to 1.00 . We then consider variable LAT availability rates across air bases. As a simple rule we define air bases as low or high demand nodes (and therefore high or low availability nodes, respectively) based upon whether their demand levels are below or above the median demand across all air bases. We then vary the availability rates according 
to three paired sets of $(0.70,0.90),(0.60,0.80)$, and $(0.50,0.70)$, which correspond to average availability rates of $0.80,0.70$, and 0.60 , respectively.

Additionally we explore introducing penalties for otherwise infeasible solutions with unmet demand. To account for unmet demand in the model the objective function is updated to include penalty costs (Equation 6) and the constraint to meet LAT demand is updated to include a dummy variable for unmet demand (Equation 7). We explore three weights $(1,10$, and 25) for the penalty that in effect act as a scaling parameter to convert unmet LAT demand into the equivalent deployment time. In practice, the $\rho$ parameter could be based on the cumulative travel times of alternative firefighting resources necessary to achieve an equivalent level of firefighting production capacity.

$$
\begin{aligned}
& \sum_{i} \sum_{j} d_{i j} Z_{i j}+\sum_{i} \rho_{i} U D_{i} \\
& \sum_{j} Z_{i j}+U D_{i} \geq k_{i} \quad \forall i
\end{aligned}
$$

Where

$U D_{i} \quad$ unmet demand at node $i$

$\rho_{j} \quad$ unmet demand penalty at node $j$

For parameterization of the model we use the same set of demands and travel times for the test network applied by Chow and Regan (2011). This test case includes 20 LATs and 12 California Department of Forestry and Fire Protection air bases. Table 1 presents summary information on the demand levels and availability classifications we used.

Table 1. Summary information on air bases in test network

\begin{tabular}{|c|c|c|c|c|}
\hline Air Base \# & $\begin{array}{c}\text { Air Attack Base } \\
\text { Name }\end{array}$ & \# of LATS & Demand Level & $\begin{array}{c}\text { Availability } \\
\text { Classification }\end{array}$ \\
\hline 1 & Hollister & 2 & 4.16 & High \\
\hline 2 & Chico & 1 & 10.4 & Low \\
\hline 3 & Fresno & 1 & 9.8 & Low \\
\hline 4 & Rohnerville & 1 & 5.58 & Low \\
\hline 5 & Sonoma & 2 & 4.8 & High \\
\hline 6 & Ukiah & 2 & 6.2 & Low \\
\hline 7 & Ramona & 2 & 9.9 & High \\
\hline 8 & Hemet & 2 & 5.12 & Low \\
\hline 9 & Redding & 2 & 5.69 & High \\
\hline 10 & Paso Robles & 2 & 5.47 & High \\
\hline 11 & Columbia & 2 & 5.18 & High \\
\hline 12 & Porterville & 1 & 4.06 & \\
\hline
\end{tabular}

\section{Results}

Figure 1 displays how total deployment time varies with LAT availability, using the first model presented in Equations 1-5. As expected, total deployment time decreases as LAT availability increases, reaching an overall minimum of 31.46 at full availability. Results are not presented below an availability rate of 0.55 because solutions are infeasible. At the rate of 0.55 total deployment time (63.64) is more than double that of full availability.

Figure 2 instead focuses on LAT air base assignments, summarizing how these assignments can vary with LAT availability. The figure compares the number of LAT assignments per air base under the baseline (full availability) scenario to the mean number of assignments across availability rates ranging from $0.55-0.95$. Results indicate substantial variation in LAT air base assignments, suggesting a high 
degree of sensitivity to LAT availability. Particular prominent differences are observed for air bases 2 and 3 (fewer assignments under baseline scenario) as well as air base 8 (more assignments under baseline scenario). Optimal LAT air base locations also differ significantly from current (as of 2011) actual LAT assignments (see Table 1).

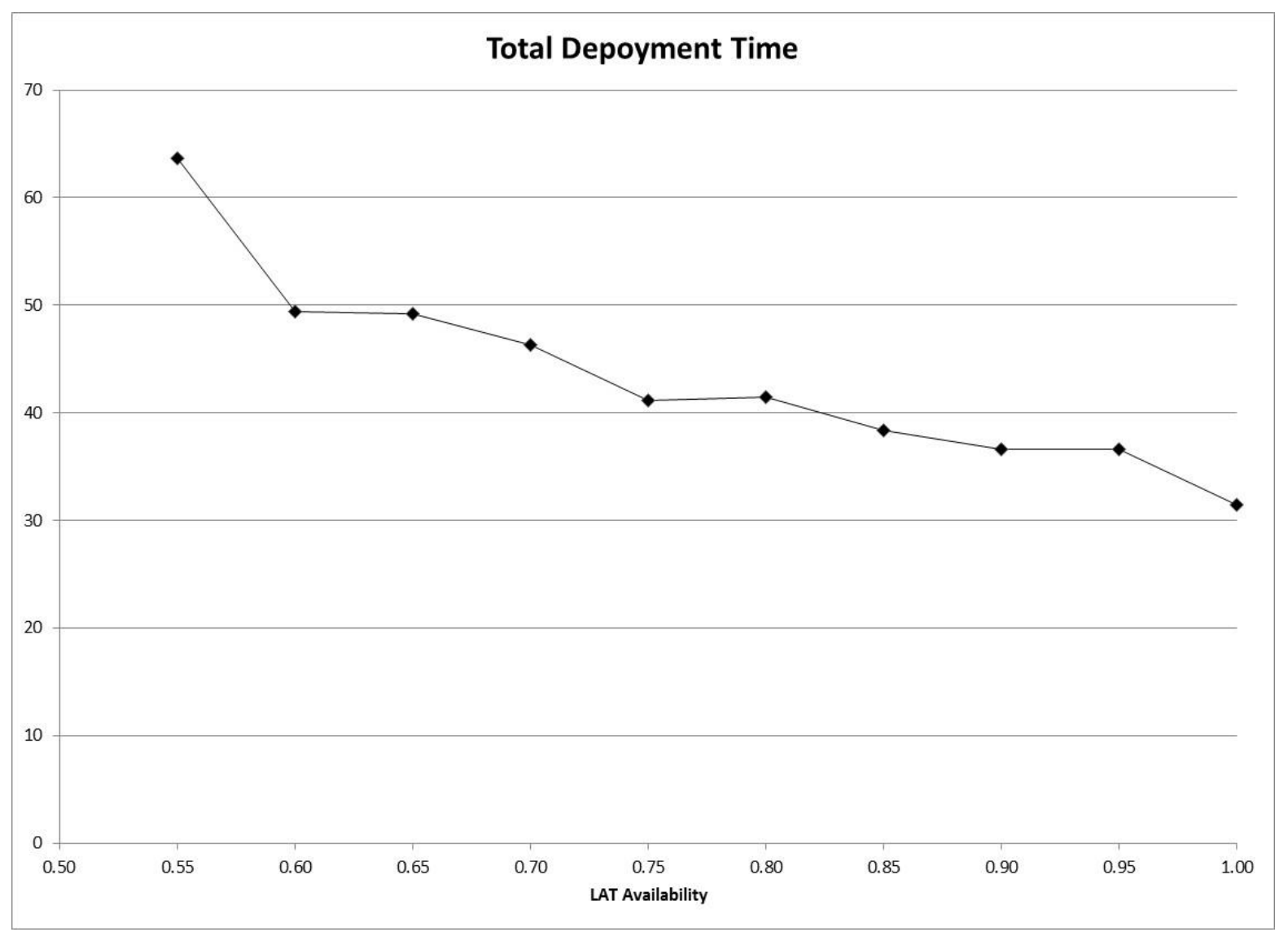

Figure 1. Total deployment time as a function of LAT availability

Table 2 compares total deployment times and LAT air base assignments across six LAT availability scenarios - those for uniform availability rates of $0.80,0.70$, and 0.60 , as well as the low/high paired sets. At least over these availability rate combinations, the model performs better with variable availability rates, and in general shows substantial sensitivity to LAT availability. This is because the model preferentially selects air bases with low demand levels and therefore higher availability rates (see Table 1). For instance compare the number of LAT assignments to air bases 2 and 3 under uniform and variable availability rates. 


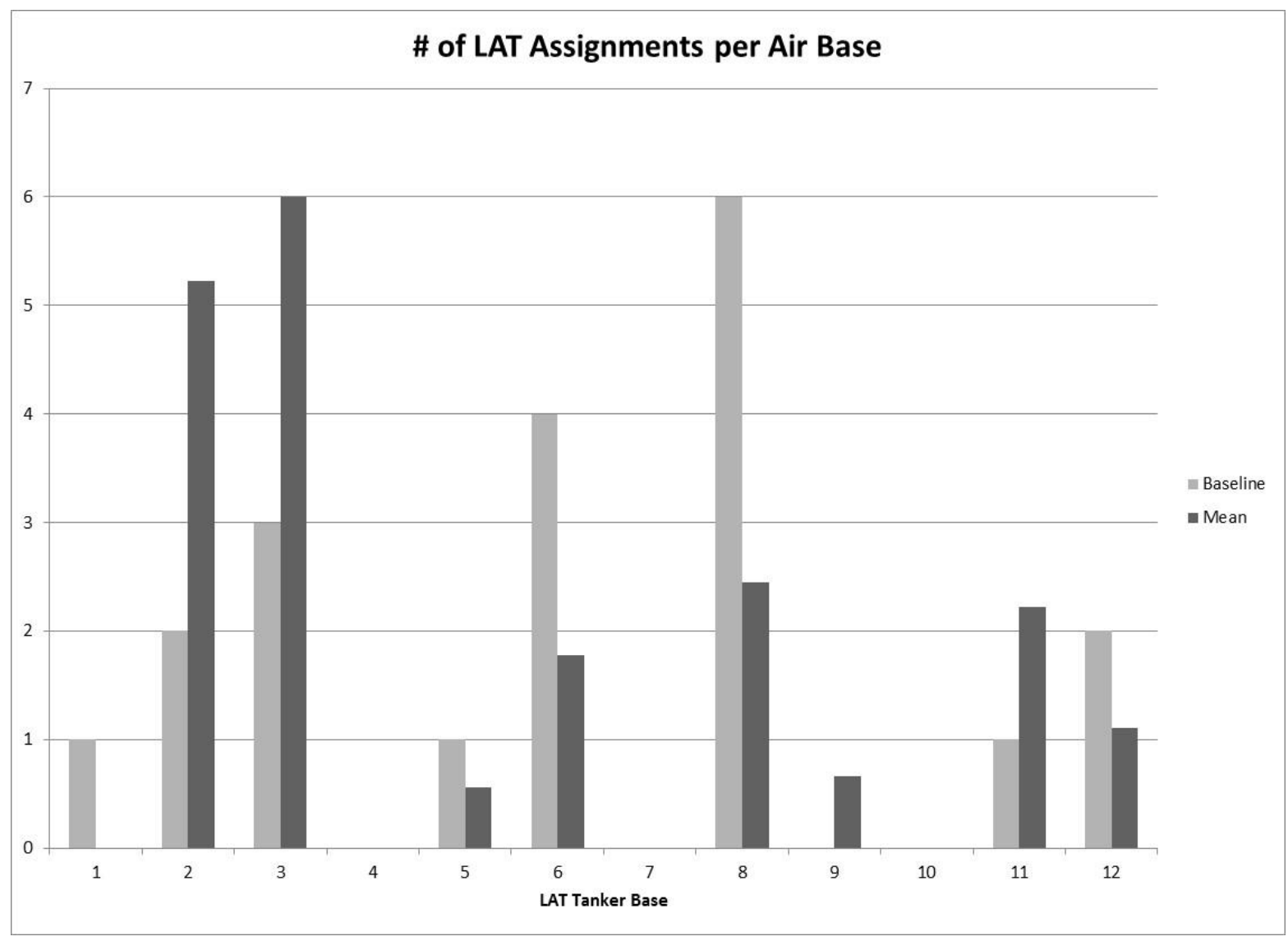

Figure 2. Number of LAT assignments per air base across different LAT availability scenarios

Table 2. Total deployment times and LAT air base assignments under different LAT availability rate scenarios

\begin{tabular}{|c|c|c|c|c|c|c|}
\hline \multirow{5}{*}{ Air Base \# } & \multicolumn{3}{|c|}{$\begin{array}{c}\text { Uniform LAT Availability Rate } \\
\text { Across Air Bases }\end{array}$} & \multicolumn{3}{|c|}{$\begin{array}{c}\text { Variable LAT Availability Rate } \\
\text { Across Air Bases }\end{array}$} \\
\hline & 0.80 & 0.70 & 0.60 & $0.70,0.90$ & $0.60,0.80$ & $0.50,0.70$ \\
\hline & \multicolumn{6}{|c|}{ Total Deployment Times } \\
\hline & 41.5 & 46.27 & 49.45 & 39.59 & 42.68 & 47.5 \\
\hline & \multicolumn{6}{|c|}{ Number of LAT Assignments per Air Base } \\
\hline 1 & 0 & 0 & 0 & 0 & 0 & 0 \\
\hline 2 & 5 & 10 & 5 & 0 & 0 & 0 \\
\hline 3 & 5 & 10 & 5 & 0 & 0 & 0 \\
\hline 4 & 0 & 0 & 0 & 0 & 0 & 0 \\
\hline 5 & 0 & 0 & 5 & 8 & 5 & 10 \\
\hline 6 & 3 & 0 & 0 & 0 & 0 & 0 \\
\hline 7 & 0 & 0 & 0 & 0 & 0 & 0 \\
\hline 8 & 4 & 0 & 0 & 6 & 5 & 0 \\
\hline 9 & 0 & 0 & 0 & 0 & 0 & 0 \\
\hline 10 & 0 & 0 & 0 & 0 & 0 & 0 \\
\hline 11 & 0 & 0 & 0 & 0 & 5 & 0 \\
\hline 12 & 3 & 0 & 5 & 6 & 5 & 10 \\
\hline
\end{tabular}


Figures 3-5 incorporate unmet demand based on the updated model incorporating Equations 6 and 7. Figure 3 displays total penalty-adjusted deployment times as a function of LAT availability, using a $\log$-scale to better differentiate results at the higher availability rates. At rates below 0.55 , where the original model becomes infeasible, objective functions with higher penalty rates begin to climb more steeply. Over the range 0.55 to full availability, results for the penalty weight of 25 are identical to results presented in Figure 1. Where the penalty for unmet demand is only 1, the solutions never fully meet all demand because it is cheaper to incur the penalty than to travel to other air bases. Figure 4 further illustrates this relationship between unmet demand and deployment time where the penalty is 1 , showing that unmet demand never drops to zero. Neither does deployment time exhibit a negative slope after availability of 0.55 (see Figure 1), again because the gains in availability are less important relative to the low penalty of not meeting demand. By contrast, Figure 5 shows the same relationships but where the penalty is 10 . Travel time rises and unmet demand drops steeply until roughly the point where the problem becomes feasible. From that point forward deployment time continues to drop as availability increases, consistent with Figure 1.

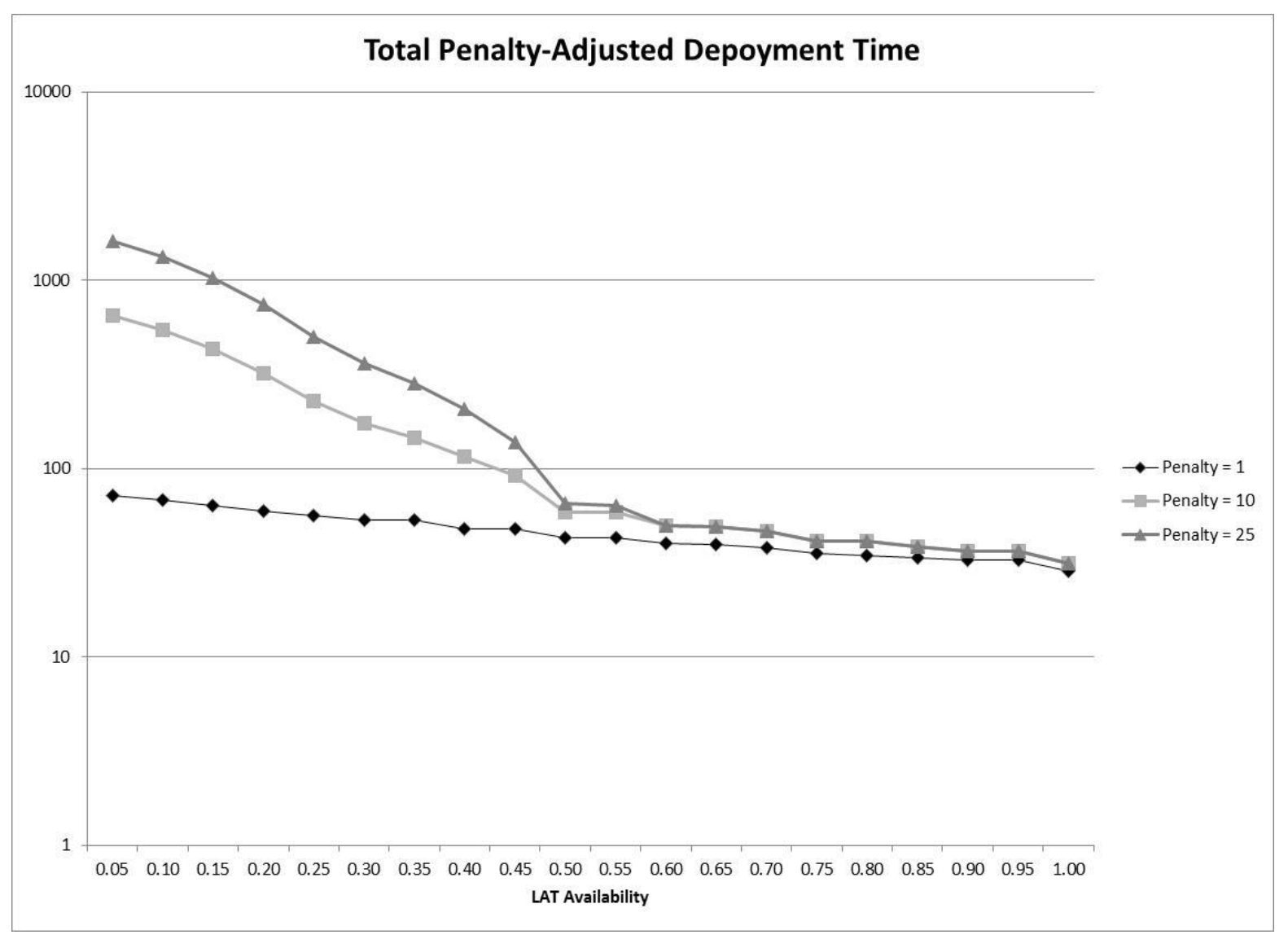

Figure 3. Total penalty-adjusted deployment time as a function of LAT availability

\section{Discussion}

We reviewed recent research indicating significantly different LAT usage patterns than has been typically assumed within LAT location and deployment optimization efforts. Specifically these models have assumed near total use for IA, whereas recent evidence suggests EA use can comprise a significant share of overall use. Additionally, recent research indicating low IA success rates on fires that receive LAT support during IA suggest possible inefficiencies in LAT usage. In response we 
augmented a mathematical optimization model to explore trade-offs between IA and EA use, and examined model sensitivity to LAT unavailability for IA efforts.

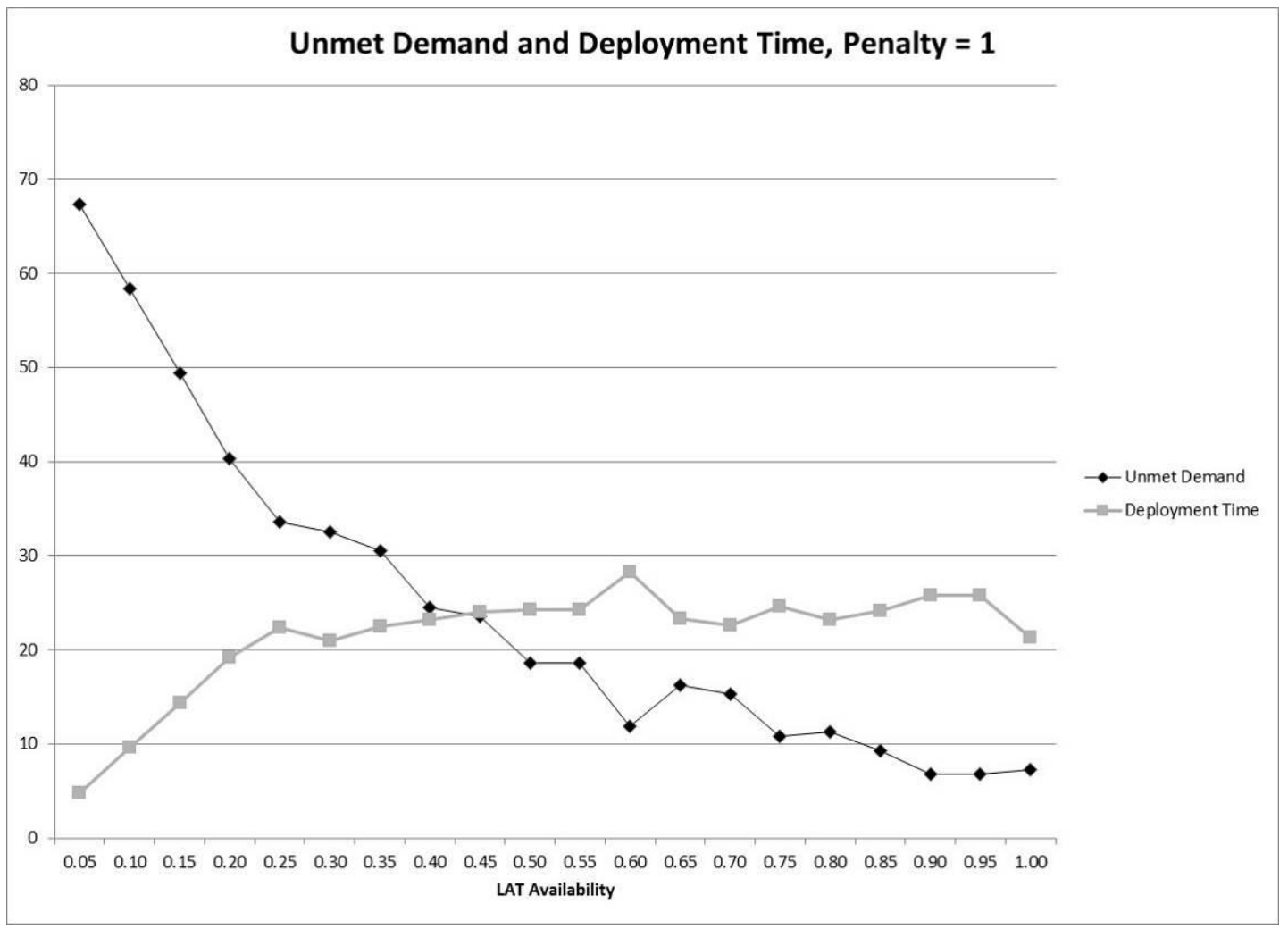

Figure 4. Unmet demand and deployment time as a function of LAT availability, penalty = 1

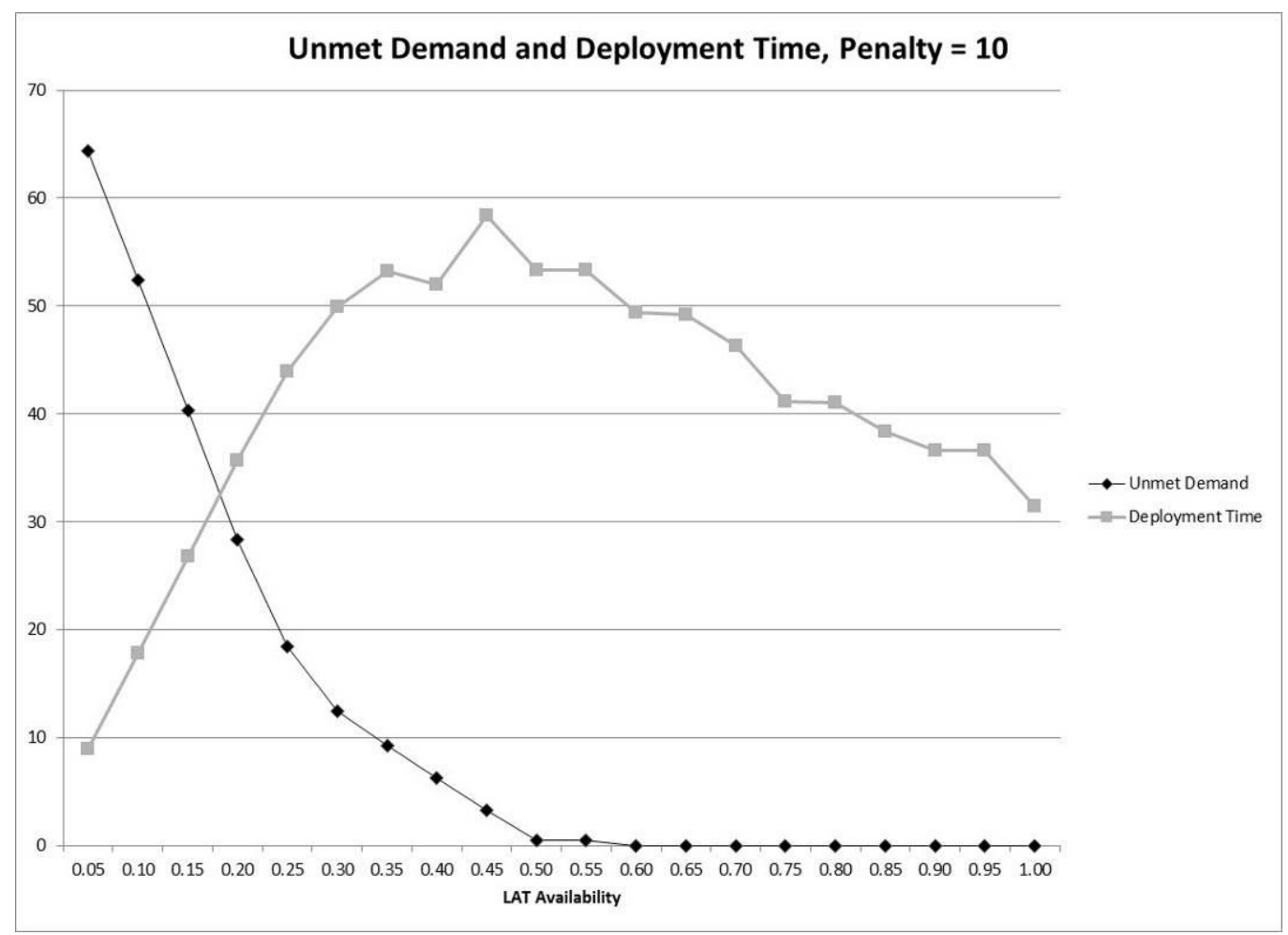

Figure 5. Unmet demand and deployment time as a function of LAT availability, penalty $=10$ 
Our results indicated that model performance degrades as LATs become less available, and that results are highly sensitive to LAT unavailability. This sensitivity is particularly evident when examining optimal LAT air base locations (the same is true for optimal LAT deployment rules, not provided here for economy of presentation). These results could carry significant implications for efficient updating of LAT location and deployment strategies, especially when considering additional real-world factors like staffing needs and air base capacities. Our results also lead to questions of how changes in fleet size could mitigate or exacerbate potential IA/EA trade-offs. A more complete model would ideally seek to better compare with a common metric the costs and benefits of LAT use for IA and EA rather than focus on degraded IA performance, although data gaps still present significant challenges to building such a model.

One immediate extension to our model is to consider a dynamic model that can relocate LATs on a daily basis in response to observed and/or predicted fire activity (Chow and Regan 2011). This extension requires a more complicated framework and increased computational demands, a verifiable ability to forecast future aerial firefighting needs, and an approach to translate relocation costs to the value of improved deployment time considering factors such as avoided damages. Further, incorporating LAT unavailability into the model on a daily basis would require a more complicated model to characterize LAT unavailability due to EA support. However, this approach can better capture the nature of a truly dynamic suppression organization that makes responsive location and relocation decisions. This modelling approach may also better illustrate opportunities for efficiency gains relative to current practice.

Additional future modelling efforts could consider variation in demand in addition to supply, could explore probabilistic efforts to better capture possible pulses of high IA activity, and adopt combined simulation-optimization efforts. Additional research to calibrate and parameterize these models is necessary as well. These efforts could seek to quantify the predictive skill of fire weather forecasts as well as the degree to which these forecasts influence suppression resource prepositioning. Critically, research efforts will need to better characterize the benefits and costs of LAT usage to move beyond the simplistic model based on travel time alone. Thus, beyond modelling efforts, continued empirical analysis of LAT usage, fire outcomes, and particularly drop effectiveness are warranted.

\section{Acknowledgements}

The Rocky Mountain Research Station and the National Fire Decision Support Center supported this effort.

\section{References}

Calkin, D. E., C. S. Stonesifer, M. P. Thompson, and C. W. McHugh (2014), Large airtanker use and outcomes in suppressing wildland fires in the United States, International Journal of Wildland Fire, 23(2), 259-271.

Chow, J. Y., and A. C. Regan (2011), Resource location and relocation models with rolling horizon forecasting for wildland fire planning, INFOR: Information Systems and Operational Research, 49(1), 31-43.Fire Program Solutions 2005

Fire Program Solutions (2005) Wildland Fire Management Aerial Application Study. Available at http://www.fs.fed.us/fire/publications/aviation/nats3_wfmaas_report_final.pdf [Verified 24 July 2014]

GAO (2013) Improvements Needed in Information, Collaboration, and Planning to Enhance Federal Fire Aviation Program Success. US Government Accountability Office, Report number GAO-13684. Available at http:// http://www.gao.gov/products/GAO-13-684 [Verified 14 July 2014] 
Keating EG, Morral AR, Price CC, Woods D, Norton D, Panis C, Saltzman E, Sanchez R (2012) Air attack against wildfires: understanding US Forest Service requirements for large aircraft. (RAND Corporation) Available at

http://www.rand.org/content/dam/rand/pubs/monographs/2012/RAND_MG1234.pdf [Verified 14 July 2014]

Plucinski, M. P., and E. Pastor (2013), Criteria and methodology for evaluating aerial wildfire suppression, International Journal of Wildland Fire, 22(8), 1144-1154.

Thompson, M. P., D. E. Calkin, J. Herynk, C. W. McHugh, and K. C. Short (2013), Airtankers and wildfire management in the US Forest Service: examining data availability and exploring usage and cost trends, International Journal of Wildland Fire, 22(2), 223-233. 